\title{
Evaluation of the Effect of Passive Smoking on Lactoferrin and AST on 12 - 15 Years Old Children and Adolescents
}

\author{
Niloofar Jenabian, ${ }^{1}$ Mahdi Pouramir, ${ }^{2}$ Mina Motallebnejad, ${ }^{3}$ Jale Bamdadian, ${ }^{4}$ and Morteza \\ Rahimi-Rad ${ }^{1, *}$ \\ ${ }^{1}$ Department of Periodontology, School of Dentistry, Babol University of Medical Sciences, Babol, IR Iran \\ ${ }^{2}$ Department of Biochemistry, Faculty of Medicine, Babol University of Medical Sciences, Babol, IR Iran \\ ${ }^{3}$ Department of Diagnosis, Babol University of Medical Sciences, Babol, IR Iran \\ 4 Babol University of Medical Sciences, Babol, IR Iran \\ *Corresponding author: Morteza Rahimi-Rad, Department of Periodontology, School of Dentistry, Babol University of Medical Sciences, Babol, IR Iran. E-mail: mortezadds@yahoo. \\ com
}

Received: July 10, 2015; Accepted: August 15, 2015

\begin{abstract}
Background: Passive smokers are involuntarily exposed to cigarette or tobacco smoke and as known, inhalation of environmental tobacco smoke is a serious threat. There is little information about the effect of passive smoking on salivary markers and periodontal indices.

Objectives: This study investigated the effect of passive smoking on lactoferrin and AST in 12 - 15 years old children and adolescents. Patients and Methods: This case-control analytic correlation type study with no-convenience random sampling method was performed on 160 children aged 12 - 15 who had smokers in their families. The eligible children were divided into two equal groups; $80 \cot ^{+} \mathrm{children}$ as case group and $80 \cot ^{-}$children as control group, matched according to age, sex and plaque index. Plaque index was obtained from all subjects. 2 cc unstimulated salivary samples were collected by spitting method. The collected specimens were tested by lactoferrin and AST kits in biochemistry were measured on the day of sampling laboratory. Gingival index Loe and Silness (GI) and Probing Pocket Depth (PPD). Results: Mean and Standard Deviation of PPD and GI was $2.01 \pm 0.077$ and $1.53 \pm 0.055$ in experimental group and $1.93 \pm 0.073$ and $1.49 \pm$ 0.046 in control group respectively $(\mathrm{P}<0.001)$. The Mean and Standard Deviation parameters of lactoferrin and AST, in the experimental group was $38.66 \pm 25.15$ and $13.45 \pm 6.33$ and in the control group $10.18 \pm 6.82$ and $6.53 \pm 2.65$ group, respectively $(\mathrm{P}<0.001)$.

Conclusions: Passive smoking can be effective on inflammatory process of periodontal and salivary biomarkers related to inflammation. Lactoferrin was 11-104 in case group and 0.5 - 38 in control group. Aspartat aminotransferase in case group was 2.64 - 30.43 and in control group it was $2.16-12.02$.
\end{abstract}

Keywords: Passive Smoker; Lactoferrin; Aspartate Aminotransferase

\section{Background}

Cigarette smoking is harmful not only for cigarette smoker but also for the people around. The results of researches about the effect of smoking on the tissues and periodontiumare different and sometimes controversial (1-3). At least one billion adults and 700 million children are breathing from the air that is polluted by cigarette smoking mostly in houses. Continin, a nicotine metabolite with a long half-life ( 8 - 20 hours) leads to higher and more stable concentration in plasma or saliva and is a good screening tool for passive smokers. In has been shown that it is related to prevalence of dental caries (4).

Children are the most vulnerable group to passive smoking (PS) because of smaller bronchial tubes and less developed immune system. There is a possibility that PS may enhance periodontal problems in children by affecting inflammatory factors (5-7). Nishida et al. in 2006 investigated the association between passive smoking and salivary markers related to periodontitis. The levels of saliva markers interleukin 1B (IL1B), lactoferrin, albumin and aspartat aminotransferase (AST) were notably increased in PS subjects noticing that AST and lactoferrin are inflammatory periodontal markers (6). In contrary to this, Rezaei and Sariri (2011) found in passive smokers lower saliva enzymes $\alpha$-amylase and lactoferrin (8).

Erdemir et al. (2004) found no inter-relationship between passive smoking and gingival index (GI), as well as periodontal pocket depth (PPD) in PS children (5).

\section{Objectives}

The present study was conducted to more elucidate the effect of PS on periodontal inflammation markers salivary lactoferrin and AST.

Copyright (C) 2015, Growth \& Development Research Center. This is an open-access article distributed under the terms of the Creative Commons Attribution-NonCommercial 4.0 International License (http://creativecommons.org/licenses/by-nc/4.0/) which permits copy and redistribute the material just in noncommercial usages, provided the original work is properly cited. 


\section{Patients and Methods}

16012 - 15 years old school children who had smoker in their family were selected and divided into two equal $\cot ^{+}$(case) and $\cot ^{-}$(control) groups. The selection criterion was cotinine kit. If the concentration of cotinine was $\geq$ $0.05 \mathrm{mg} / \mathrm{mL}$ they were categorized as $\cot ^{+}$and if less than that cot ${ }^{-}$The subjects were clinically healthy and had not received any antibiotics for the last 2 months and had no active caries.

\subsection{Procedure}

Parents of all participants signed written consent forms and helped the investigators to fill out the questionnaire. This study was conducted according to ethical code of university ethics committee and the proposal was approved by dental material of research center.

Subjects were matched according to age, gender and Loe and Silness plaque index. PPD was measured in all subjects with a Williams periodontal probe in four sites of the teeth which are mesiobuccal, distobuccal, buccal and lingual, and is determined by average of these sites. PPD is measured from the depth of pocket to the gingival margin. Before collecting the samples participants had to rinse their mouth with water for 1 minute to remove any existing debris or blood and were asked not to eat anything at least for 2 hours.

Two millimeter non-stimulated saliva was collected in test tube with spitting method 1 - 2 times every minute for 10 minutes. While collecting saliva the person was in sitting, comfortable position. After obtaining saliva the test tubes were covered by sealed parafilm and sent to biochemistry lab as soon as possible. Continin level of samples was investigated with ELISA method. Concentration of AST enzyme was measured by Pars Azmoon AST kit and Jenway GSO6 UV/Vis Spectrophotometer. Lactoferrin was measured by ELISA technique in biochemistry lab of Babol University of Medical Sciences.

\subsection{Laboratory Steps}

\subsubsection{Lactoferrin Kit Lab Method}

Lactoferrin EIA is an enzyme related immunologic method. The lactoferrin of samples is obtained through monoclonal antibody $(\mathrm{Ab})$ that is placed on micro plates. Monoclonal Ab specific for lactoferrin attached to bioten is added to the samples. Lactoferrin is attached to antibodies and the sandwich is formed. Then, Streptavidin peroxidase solution is added. Streptavidin has tendency to bioten and with adding Ophenylenediamine the dye is formed. The intensity of this dye within the wavelength of $450 \mathrm{~nm}$ is in direct relation with lactoferrin.

\subsubsection{AST Kit Lab Method}

The basis of the test is that L-Aspartate reacts with 2-oxoglutarate by help of AST enzyme. In the next step oxoglutrate reacts with NADH by help of maleate dehydrogenase and maleate and NAD are produced. Different absorption of NADH in the wavelength of $340 \mathrm{~nm}$ is an indicator of AST activity.

\subsubsection{Preparing Solution}

This test can be done with one or two solutions. In this study single solution was chosen.

Indicator No I: LDH (Lactatedehydrogenase), MDH (Maleat dehydrogenase) L-Aspartate, TRIS Buffer ( $\mathrm{pH}=7.8$ ).

Indicator No II: NAPH, 2-oxglutarate.

No I and II solutions were ready for use. For performing a single solution test, the solution No I and II were mixed with a 4 to 1 ratio $(20 \mathrm{~mL}$ solution No I and $5 \mathrm{~mL}$ solution No II). 100 micro liter sample saliva and 1000 micro liter from the mixed sample were mixed. Light absorption was measured after 1 minute. The exact difference between light absorptions after 1, 2, and 3 minutes was measured. The total of these three values was divided into 3 and multiplied by 1985 .

\subsection{Statistical Analysis Methods}

The data was analyzed by SPSS 18 and t-test and MannWhitney U test.

\section{Results}

This study was carried out on $80 \cot ^{+}$children as case and $80 \cot ^{-}$as control group. The result was as follows (Table 1): Gingival index in case group (Passive smoking) was between $1.42-1.61$ and control group between 1.40 1.54. The Mean and Standard Deviation in case and control group was $1.53 \pm 0.055$ and $1.44 \pm 0.046$, respectively which were statistically significant $(\mathrm{P}<0.001)$. Probing pocket depth in case group was between $1.9-2.12$ and in control group 1.85 - 2.06. The Mean and SD in case and control group was $2.01 \pm 772 \%$ and $1.43 \pm 773 \%$, respectively, which was significant $(\mathrm{P}<0.001)$.

\begin{tabular}{|c|c|c|c|}
\hline & Case Group b & Control Group b & PValue \\
\hline Gingival index & $1.53 \pm 0.055$ & $1.44 \pm 0.046$ & $0.000^{\mathrm{C}}$ \\
\hline PPD & $2.01 \pm 0.0772$ & $1.93 \pm 0.0733$ & $0.000^{\mathrm{C}}$ \\
\hline Lactoferrin & $38.66 \pm 25.15$ & $10.18 \pm 6.82$ & $0.000^{\mathrm{C}}$ \\
\hline Aspartat aminotransferase & $13.45 \pm 6.33$ & $6.53 \pm 2.65$ & $0.000^{\mathrm{d}}$ \\
\hline
\end{tabular}




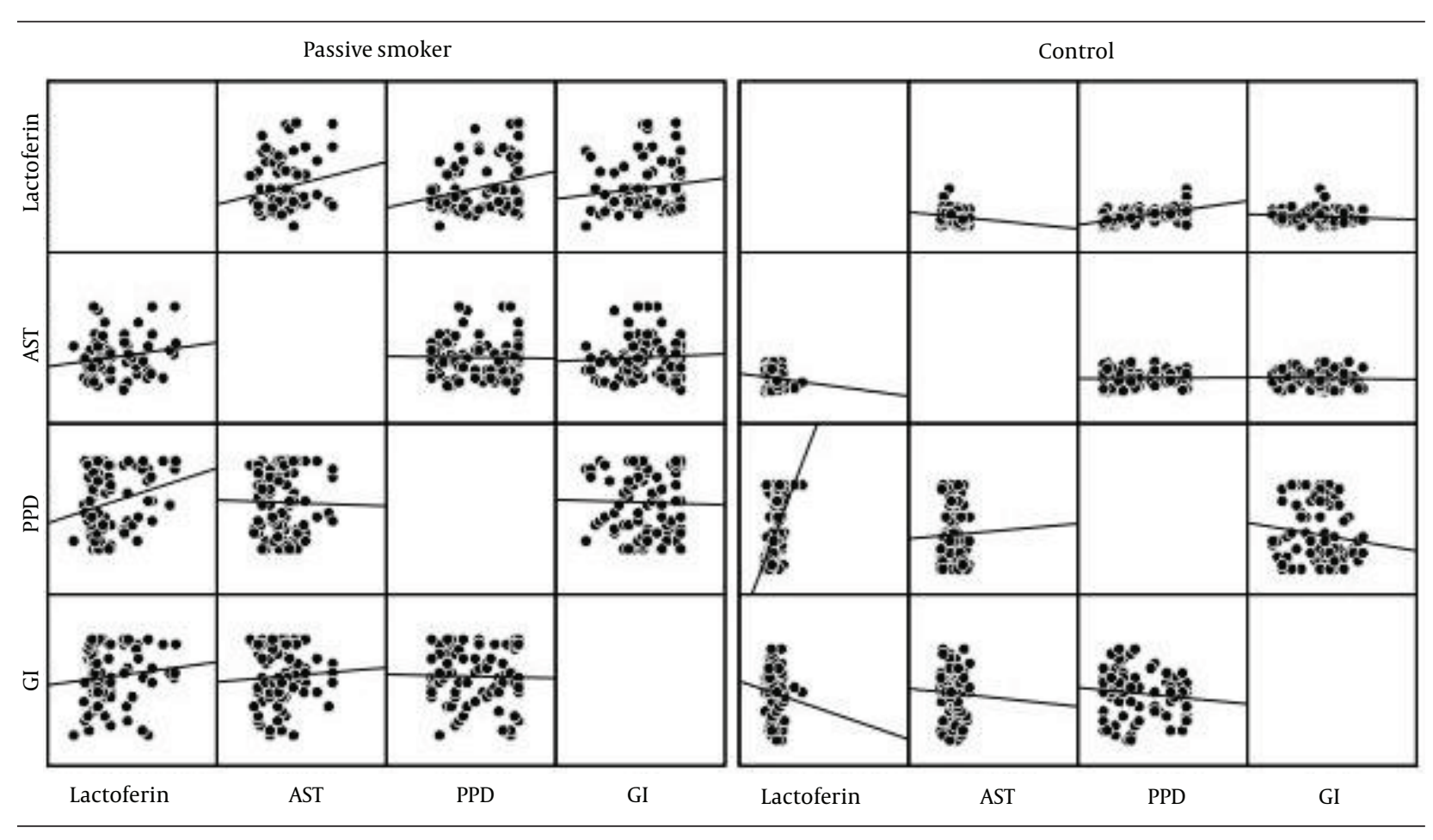

Figure 1. Relation of PPD, GI, AST, and Lactoferrin in Case and Control Group

\section{Discussion}

This study was done on 160 school children (12 - 15 years old). The average level of lactoferrin and AST in saliva was assessed. This was in passive smokers significantly higher compared with control group $(\mathrm{P}<0.001)$. GI and PDD indices were also higher in case group which was different from the results of the study of Erdemir et al. (2004) (5). They didn't find significant difference between PS and nonPS subjects. This may be due to smaller sample size. The difference between societies in culture and public health conditions could be another reason for the controversy.

In the study carried out by Rezaei and Sariri (2011) (8), periodontal condition, saliva enzymes and the saliva flow were analyzed in 30 school children aged 18 - 22 years and 30 controls. The results of the study showed PPD $\leq 3 \mathrm{~mm}$ in control group and $3<$ PPD $<6$ in $90 \%$ of PS. The result was not in accordance with our study.

Another result of this research was the activity of saliva proteins including amylase, peroxidase and lactoferrin. The activity of amylase and lactoferrin in passive smokers is reduced in comparison to control group but the activity of peroxidase is increased. This means that some saliva proteins are increased in PS while others are decreased. The controversy in the results may be due to differences in sampling methods and sampling society (8).

Nishida et al. in a study (2006) evaluated the effect of PS on saliva markers in periodontitis. The result showed that saliva markers such as AST, lactoferrin and albumin, IL-1 $\beta$ in $\mathrm{PS}$ is increased in comparison to non-PS $(\mathrm{P}<0.001)(6)$.
Nishida et al. in a 2- year longitudinal study estimated relationship between saliva markers and PS concluded that the average of saliva markers such as AST and ICT in PS was higher than in control group with a significant statistical difference between groups (9).

Arbes et al. (2001) showed that GI and PPD were significantly higher in PS subjects than in control group $(\mathrm{P}<$ $0.05)(10)$. The results of these three studies are in accordance with our study.

According to the results of this study there is coincidence between periodontal saliva markers and PS. Therefore PS can affect periodontal condition and inflammatory saliva markers.

\section{References}

1. National Health and Medical Research Council. Canberra: 1997. The health effects of passive smoking.

2. Sikorska-Jaroszynska MH, Mielnik-Blaszczak M, Krawczyk D, Nasilowska-Barud A, Blaszczak J. Passive smoking as an environmental health risk factor. Ann Agric Environ Med. 2012;19(3):547-50.

3. Martinez-Sanchez JM, Fernandez E, Fu M, Pascual JA, Ariza C, Agudo A, et al. Assessment of exposure to secondhand smoke by questionnaire and salivary cotinine in the general population of Barcelona, Spain (2004-2005). Prev Med. 2009;48(3):218-23.

4. Charalabopoulos K, Assimakopoulos D, Karkabounas S, Danielidis V, Kiortsis D, Evangelou A. Effects of cigarette smoking on the antioxidant defence in young healthy male volunteers. Int J Clin Pract. 2005;59(1):25-30.

5. Erdemir EO, Sonmez IS, Oba AA, Bergstrom J, Caglayan O. Periodontal health in children exposed to passive smoking. J Clin Periodontol. 2010;37(2):160-4. 
6. Nishida N, Yamamoto Y, Tanaka M, Maeda K, Kataoka K, Nakayama $\mathrm{K}$, et al. Association between passive smoking and salivary markers related to periodontitis. $J$ clin periodontol. 2006;33(10):717-23.

7. Zappacosta B, Manni A, Persichilli S, Boari A, Scribano D, Minucci A, et al. Salivary thiols and enzyme markers of cell damage in periodontal disease. Clin Biochem. 2007;40(9-10):661-5.

8. Rezaei A, Sariri R. Periodontal Status, Salivary Enzymes and Flow
Rate in Passive Smokers. Pharmacologyonline. 2011;3:462-76.

9. Nishida N, Yamamoto Y, Tanaka M, Kataoka K, Kuboniwa M, Nakayama $\mathrm{K}$, et al. Association between involuntary smoking and salivary markers related to periodontitis: a 2-year longitudinal study.J Periodontol. 2008;79(12):2233-40.

10. Arbes SJ, Agustsdottir H, Slade GD. Environmental tobacco smoke and periodontal disease in the United States. Am J Public Health. 2001;91(2):253-7. 